\title{
CONSIDERAÇÕES SOBRE A RESSIGNIFICAÇÃO DA SUBJETIVIDADE EM MERLEAU-PONTY
}

\author{
[REMARKS ON REDEFINITION OF SUBJECTIVITY IN MEELEAU-PonTy]
}

\author{
Renato dos Santos* \\ Pontifícia Universidade Católica do Paraná
}

\begin{abstract}
Resumo: Este artigo visa analisar como Merleau-Ponty, após evidenciar os limites do cogito cartesiano e postular um cogito tácito, propõe uma nova noção de subjetividade na obra de 1945, Fenomenologia da percepção. Trata-se não mais de uma subjetividade que se compreende a si mesma sem a necessidade do mundo fenomênico, bem como do outro, mas, ao contrário, uma subjetividade que somente se reconhece através da encarnação no mundo sensível. Por outro lado, não se trata de negar o cogito postulado por Descartes, mas de mostrar que, antes de um "eu penso", existe um "eu existo". Nesse sentido, a subjetividade passa a caracterizar-se como dependente e indeclinável; pois, ela somente se reconhece através do mundo e do outro, e, ao mesmo tempo, a despeito de necessitar do exterior para se reconhecer, sua ipseidade não se anula em vista da sua encarnação.
\end{abstract}

Palavras-chave: Cogito; Cogito tácito; Subjetividade; Merleau-Ponty
ABSTRACT: This article aims to analyze how Merleau-Ponty, after evidencing the limits of the cartesian cogito and postulating a tacit cogito, proposes a new notion of subjectivity in the work of 1945, Phenomenology of perception. It is no more a subjectivity that understands itself without the necessity of the phenomenal world, as well as of the other, but on the contrary, a subjectivity that is only recognized through incarnation in the sensible world. On the other hand, it is not a question of denying the cogito postulated by Descartes, but of showing that, before a "I think", there is a "I exist". In this sense, subjectivity becomes characterized as dependent and indeclinable; for it only recognizes itself through the world and the other, and at the same time, in spite of needing the outside to recognize itself, its ipseity does not cancel out in view of its incarnation.

KEYwORDS: Cogito; Tacit cogito; Subjectivity; Merleau-Ponty

\section{INTRODUÇÃO}

a modernidade, com o racionalismo - ou intelectualismo -, representado por
Descartes e o criticismo kantiano, e o empirismo, conforme desenvolvido por Locke, é marcada, de forma decisiva, a discussão em torno da questão da percepção. Para a ontologia cartesiana, fundada na dicotomia sujeito e objeto, ou res cogitans - dimensão do pensamento como essência da subjetividade - e res extensa - dimensão do horizonte sensível - a percepção direta dos fenômenos do mundo sensível deixam de ter importância, posto que cabe ao cogito a capacidade de organizá-los e representá-los.

Quando Descartes, na Segunda Meditação, expõe o exemplo do pedaço de cera, fica evidente a soberania do pensamento em relação à percepção fundada no sensível. Segundo Descartes (2005, p. 49-50), quando retirado da colmeia um determinado pedaço de cera, * Doutorando (Bolsista CAPES) em Filosofia no Programa de Pós-Graduação em Filosofia da Pontifícia Universidade Católica do Paraná.m@ilto: renatodossantos1@hotmail.com 
este também possui várias qualidades; mantém sua doçura do mel, da mesma forma, ocorre com o aroma das flores de que foi recolhido; sua cor, sua grandeza, enfim, todas as características de um corpo encontram-se nesse pedaço de cera. No entanto, ao aproximar o pedaço de cera do fogo, todas as qualidades sensíveis desaparecerão: sua dureza, cor, forma rígida, cheiro, odor, entre outras.

Com isso, pode-se dizer que é a mesma cera? Por certo que sim. Não obstante, o que possibilita dizer que é a mesma cera não são os sentidos, mas a capacidade de julgar do espírito que consegue distinguir a verdade do erro, que reconhecerá que a cera derretida é ela mesma. Portanto, como afirma Merleau-Ponty (2004, p. 4), "a verdadeira cera não é vista com os olhos. Só podemos concebê-la pela inteligência".

A partir do exemplo anterior, é cabível notar que se o ato de "ver" está submetido à averiguação criteriosa do espírito, este deixa de ser uma faculdade do corpo como capacidade sensível, e passa a ser mera ação puramente reflexiva. Nesse aspecto, a percepção se reduz "a um mero registro das excitações da retina, tornando-se uma operação intelectual em que os dados sensoriais se neutralizam sob uma 'síntese ativa' do entendimento" (SILVA, 2009, p. 50).

$\mathrm{Na}$ crítica ao intelectualismo, Merleau-Ponty não deixa de observar também o criticismo kantiano, como uma filosofia que reproduz muitos traços da perspectiva cartesiana. Assim, Descartes e Kant, sobretudo, nos diz Merleau-Ponty (2011, p. 4), desligaram o sujeito ou a consciência, "fazendo ver que eu não poderia apreender nenhuma coisa existente se primeiramente eu não me experimentasse existente no ato de apreendêla”. O que Merleau-Ponty faz notar, tanto em Descartes quanto em Kant, é o fato de que eles "fizeram aparecer à consciência, a absoluta certeza de mim para mim, como a condição sem a qual não haveria absolutamente nada, e o ato de ligação como o fundamento do ligado" (MERLEAU-PONTY, 2011, p. 4).

Em Kant, a unidade da consciência é "contemporânea da unidade do mundo", como mostra Merleau-Ponty (2011, p. 4). Por esse motivo, se analisarmos com atenção como ocorre o "ato de conhecer" kantiano, perceberemos que ele desemboca em um "pensamento constituinte ou naturante que funda interiormente a estrutura característica dos objetos" (MERLEAU-PONTY, 2006, p. 308). Em outros termos, quando Kant toma a consciência como "meio universal", a percepção "torna-se, por isso mesmo, uma "variedade da intelecção", (MOUTINHO, 2004, p. 268).

Se, no intelectualismo, a percepção foi reduzida à representação do pensamento, para o empirismo ela se reduz a um feixe de unidades atômicas, de sensações. Para MerleauPonty, porém, a sensação já é provida de um sentido, mas somente quando considerada integrada dentro do horizonte perceptivo; fora desse contexto, como é o caso do empirismo, ela não passa de um conceito abstrato. Para essa filosofia, os dados perceptivos são reduzidos ao que é fornecido "pelos órgãos dos sentidos, às impressões sensíveis, às qualidades, as quais se definem pelas propriedades físicas e químicas dos estímulos" (DIAS, 1989, p. 24-25).

A percepção, observa Merleau-Ponty (2011, p. 46), é construída com estados de consciência, "assim como se faz uma casa com pedras, e se imagina uma química mental que faça esses materiais se fundirem em um todo compacto". Assim, o empirismo é conduzido à descrição de processos cegos, de modo que não há espaço para um sujeito vivo, mas um sujeito que opera como "uma máquina de calcular que não sabe porque seus resultados são verdadeiros" (MERLEAU-PONTY, 2011, p. 38).

Segundo Merleau-Ponty, o postulado empirista sobre a percepção consiste em deduzir o dado daquilo que pode ser fornecido pelos órgãos dos sentidos, o que implica na construção de uma experiência artificial e, ao mesmo tempo, de um mundo e de um sujeito também artificiais. Conforme explica Isabel Matos Dias (1989, p.25), o sujeito que o empirismo buscava objetivamente explicar se dá a partir de dispositivos cognitivos, isto é, "reduz-se a uma consciência isolada, incapaz de dar conta da objectividade do mundo". Nessa perspectiva: 
Não pode mais haver espírito objetivo: a vida mental retira-se em consciências isoladas e abandonadas apenas à introspecção [...]. A percepção assim empobrecida torna-se uma operação de conhecimento, um registro progressivo das qualidades e de seu desenrolar mais costumeiro, e o sujeito que percebe está diante do mundo como o cientista diante de suas experiências (MERLEAU-PONTY, 2011, p. 50, grifos do autor).

Para Merleau-Ponty (2011, p. 70), o empirismo permanece na crença dogmática do mundo como totalidade dos acontecimentos espaço-temporais e, além disso, concebe a consciência como um "cantão" desse mundo. Já o racionalismo rompe com o mundo em si, visto que ele é constituído pela operação da consciência, mas essa consciência constituinte, ao invés de ser abstraída diretamente, é construída de forma a tornar possível a ideia de um ser absolutamente determinado.

$\mathrm{Na}$ verdade, a despeito do empirismo e do racionalismo confrontarem-se epistemologicamente, existe um parentesco entre os dois bem mais profundo do que se pode conceber. Na lógica do sujeito e do objeto, "passa-se de uma objetividade absoluta a uma subjetividade absoluta, mas esta segunda ideia vale exatamente tanto quanto a primeira e só se sustenta contra ela, quer dizer, por ela" (MERLEAU-PONTY, 2011, p. 69). Assim, o "gene" que atesta o parentesco entre o racionalismo e o empirismo é, precisamente, o ideal de subjetividade absoluta forjada na modernidade: "Sejam quais forem as discordâncias, os modernos têm em comum a ideia de que o ser da alma ou o ser-sujeito não é um ser menor, que talvez seja a forma absoluta do ser" (MERLEAU-PONTY, 1991, p. 168).

\section{A Crítica de Merleau-Ponty à SubJetividade Cartesiana}

Segundo Merleau-Ponty, há, no retorno cartesiano ao $\mathrm{Eu}$, a descoberta que insiste em ressurgir sempre que se tenta compreender como o sujeito organiza sua experiência, qual seja, que o Eu já possui os projetos das coisas transcendentes da experiência e, dessa maneira, a experiência "é reduzida a uma soma de acontecimentos psicológicos dos quais Eu seria apenas o nome comum ou a causa hipotética" (MERLEAU-PONTY, 2011, p. 497).

Com a redução cartesiana, vimos também que o eu reconhece a si mesmo de imediato, porque ele é seu saber de si e de todas as coisas, e que "conhece sua própria existência não por constatação de um fato dado, ou por inferência a partir de uma ideia de si mesmo, mas por contato direto com essa ideia" (MERLEAU-PONTY, 2011, p. 496-497). A natureza desse eu é de tal forma que se abstém da própria condição temporal e espacial do mundo, visto que ele tem o poder de abarcar e antecipar os acontecimentos temporais numa só intenção, a ponto de podermos até mesmo afirmar que esse espírito se equivale a "Deus".

Assim sendo, o cogito se afirma de maneira absoluta, já que ele se reconhece a si mesmo e não depende de nada para se reconhecer. Nessa direção, o sujeito cartesiano opera de maneira privada, tornando-se assim impossível a existência de outras consciências. Para Merleau-Ponty, na medida em que tenho consciência absoluta de mim mesmo torna-se inexequível haver espaço para outrem no horizonte visado por esse cogito. A relação com meu pensamento torna-me privado em mim mesmo, na medida em que o cogito proíbe qualquer possibilidade de ultrapassagem de outra consciência na dimensão que meu cogito supervisiona. Dessa forma, definitivamente não há abertura a "um Outro para este Eu que constrói a totalidade do ser e sua própria presença no mundo, que se define pela "posse de si" e que só encontra no exterior aquilo que ele ali colocou" (MERLEAU-PONTY, 2011, p. 499).

Se for verdade que o sujeito cartesiano se caracteriza pela posse de si mesmo, e se mostra, pois, como uma existência indubitável, devido ao fato de que a própria dúvida implica que ele retorne ao auto-reconhecimento da subjetividade, também é verdade que todo "desdobramento de uma potência constituinte que conteria eminente e eternamente em si mesma toda visão e sensação possíveis" (MERLEAU-PONTY, 2011, p. 503) dispensaria 
o esforço transcendental de sair-se de si em direção ao mundo para ter os dados sensíveis para fazer essa operação.

Em outros termos, para Descartes, trata-se de afirmar a certeza do pensamento de ver e negar a existência real da coisa vista, implicando assim a redução do mundo a um cogitatum, no sentido de que o mundo é transposto para o mesmo estatuto existencial do 206 cogito. Entretanto, segundo Merleau-Ponty (2011, p. 500), o que o pensamento cartesiano ignora é o fato de que "não se pode tratar de manter a certeza da percepção recusando a certeza do percebido", visto que a própria "certeza de uma possibilidade não é senão a possibilidade de uma certeza" (MERLEAU-PONTY, 2011, p. 501), isto é, o pensamento de ver não é outra coisa senão a própria visão em ideia, o que, ao contrário, seria impossível ter a visão em ideia se não tivéssemos a própria experiência da visão na realidade.

Assim, Merleau-Ponty evidencia que o cogito somente realiza suas operações a partir de sua presença efetiva no mundo. Todas as projeções reflexivas são retiradas da experiência intrínseca do sujeito no mundo dos fenômenos, isto é, "não existe juízo que não brote da própria configuração dos fenômenos" (MERLEAU-PONTY, 2011, p. 503). Para Merleau-Ponty (2011, p. 503), o que podemos constatar no cogito não é uma imanência psicológica, nem tampouco inerência dos fenômenos à consciência privada, mas certa espécie de "movimento profundo de transcendência que é meu próprio ser, o contato simultâneo com meu ser e com o ser do mundo" (MERLEAU-PONTY, 2011, p. 503).

Não obstante, é necessário atentar-se que nessa relação entre o cogito e o mundo não há sintetização por parte de uma consciência, pois, caso contrário, impediria o movimento de transcendência do mundo. Isto é, para que tal transcendência seja possível, é necessário que exista a comunhão da percepção em relação ao percebido e que eles estejam imbricados na temporalidade, de modo que o espectador e o mundo não sejam estagnados, encerrados em si mesmos. Segundo Moutinho (2006, p. 225), o que um cartesiano ignora não é o fato de o mundo ser irredutível, mas sim que o mundo está em curso temporal; é a temporalidade, finalmente, que inviabiliza a constituição e a redução do mundo.

A temporalidade impede que a constituição do sentido do mundo seja eterno, posto que o mundo ininterruptamente segue sua marcha temporal. Assim, se for verdade que o mundo está sempre numa constante atualização, é verdade também que o sentido de algo está sempre por se fazer, visto que o objeto pelo qual se tem sentido não é fixo, estagnado, mas em fluxo. Desse modo, a desconstrução da noção cartesiana da operação interna do sentido das coisas parece ter alcançado seu êxito.

A fim de advogar sua doutrina, um cartesiano ainda poderia argumentar usando a questão dos sentimentos, os quais, à primeira vista, são os que estão mais íntimos da experiência interna, tal como a vontade e o amor. De fato, quando se trata da percepção dos sentimentos "a consciência, parece, retoma seus direitos e a plena posse de si mesma se considero minha consciência dos fatos psíquicos" (MERLEAU-PONTY, 2011, p. 504). Os sentimentos parecem serem, antes de tudo, operações interiores que fabricam seus próprios objetos. Poder-se-ia afirmar que o querer é ter consciência de um objeto como valioso, ou então que o sentimento de amar existe na medida em que se tem a consciência de um objeto amado. Assim, o cogito, ao menos nesse contexto, manteria sua certeza de si na medida em que constitui os objetos de sentimentos.

No entanto, para que isso fosse possível seria preciso que tudo que dissemos sobre a percepção fosse falso. É fato que existem sentimentos enganosos, ilusões, sentimentos falsos que preenchem nossa vida psíquica. Por vezes, vivemos momentos transbordados de sentimentos amorosos, sejam eles felizes ou infelizes, decepções, sofrimentos, etc. Estes sentimentos nos parecem no momento presente serem permanentes, imutáveis, eternos. Entretanto, ao passar do tempo, à luz de novas experiências, muito provavelmente estes sentimentos venham revelar seu contrário. O que hoje é ódio, amanhã poderá ser amor, e vice-versa. Nas palavras de Merleau-Ponty (2011, p. 508), "é a verdade de seus sentimentos futuros que fará aparecer a falsidade de seus sentimentos presentes".

Nesse sentido, podemos perceber que até mesmo os sentimentos estão ancorados na 
própria estrutura da percepção. Ou seja, se os sentimentos fossem simples representação do cogito, então eles não mudariam, visto que as vivências em nada influenciariam neles. Uma ilusão amorosa somente pode ser constatada que se tratou efetivamente de ilusão, com o passar do tempo. Se somos suscetíveis à ilusão, é porque a própria "percepção é modalidade de uma função na qual são ainda indistintos o verdadeiro e o falso, na qual não há ainda nenhuma certeza intrínseca, como supõe o intelectualismo" (MOUTINHO, 2006, p. 227).

Para Merleau-Ponty, o amor, a raiva, a vontade, não são expressões de pensamentos de amar, de odiar e de querer, mas, inversamente, a certeza desses pensamentos "provém da certeza dos atos de amor, de raiva ou de vontade, dos quais estou seguro porque eu os faço" (MERLEAU-PONTY, 2011, p. 511-512). Notemos aqui que a gênese de todos os sentimentos provém do ato, ou melhor, do engajamento do sujeito numa situação. Em outras palavras, é "em minha relação com as coisas que eu me conheço, a percepção interior vem depois, e ela não seria possível se eu não tivesse tomado contato com minha dúvida vivendo-a até em seu objeto" (MERLEAU-PONTY, 2011, p. 512).

Desse modo, qualquer dúvida, por mais radical que ela seja, precisa primeiramente se engajar no mundo. Como diz Merleau-Ponty (2011, p. 512-513, grifo do autor):

\begin{abstract}
Na proposição 'Eu penso, eu sou', as duas afirmações são equivalentes, sem o que não haveria Cogito. Mas ainda é preciso entender-se sobre o sentido dessa equivalência: não é o Eu penso que contém eminentemente o Eu sou, não é minha existência que é reduzida à consciência que dela tenho, é inversamente o $\mathrm{Eu}$ penso que é reintegrado ao movimento de transcendência do $\mathrm{Eu}$ sou e a consciência à existência.
\end{abstract}

É verdade, não obstante, diz Merleau-Ponty, que parece haver certa coincidência comigo mesmo, senão, no que vimos anteriormente, da dimensão do sentimento e do desejo, ao menos no âmbito do entendimento, tal como, por exemplo, as formas geométricas que compõe o chamado "entendimento puro" do sujeito. Trata-se, pois, de afirmar que a ideia do triângulo se faz presente no sujeito como categoria a priori da razão, e isso se confirmaria na medida em que o sujeito se defrontar com a experiência. Por uma espécie da essência (eidos) de uma figura que o sujeito já possui, será por meio dela que ele desvelará toda "verdade" a posteriori.

Todavia, segundo Merleau-Ponty, o triângulo somente se revela a partir do momento em que o sujeito realiza o movimento no próprio mundo. Não se trata, pois, do fenômeno em sua configuração em ideia, mas como experiência na natureza. Tomando como exemplo um geômetra quando vai realizar a construção, ele primeiramente se desloca por meio da experiência naquele espaço onde será realizada a obra. Assim, podemos inferir que trata-se, inicialmente, de uma intencionalidade que o conduz ao espaço para tirar dali a noção "triângulo". Ou seja, "é enquanto eu me situo em um ponto e dali tendo para outro ponto, enquanto para mim o sistema das posições espaciais é um campo de movimentos possíveis" (MERLEAU-PONTY, 2011, p. 516).

Desse modo, a apreensão concreta da essência de um triângulo se dá, precisamente, por uma espécie de "fórmula de atitude, uma certa mobilidade de meu poder sobre o mundo, uma estrutura" (MERLEAU-PONTY, 2011, p. 516). É através do corpo em situação que o geômetra pode realizar a ideia de triângulo. Podemos dizer, então, que o geômetra é um sujeito motor, na medida em que o corpo próprio é o que permite realizar um "movimento gerador do espaço". Ademais, nosso corpo não é somente a condição de possibilidade da "síntese geométrica, mas ainda de todas as operações expressivas e de todas as aquisições que constituem o mundo cultural” (MERLEAU-PONTY, 2011, p. 519).

\title{
O COGITO TÁCITO E O COGITO FALADO
}

Conforme vimos até aqui, tanto a percepção das coisas, quanto a dimensão dos 
sentimentos (o amor e o desejo) e até mesmo a questão do triângulo, os quais, o cogito os consideram como operações constitutivas de seu poder de julgar, implicam na afirmação da absoluta posse de si mesmo. Porém, ao considerar a imbricação do corpo no mundo, Merleau-Ponty mostrou que justamente tais fenômenos (o sentido do mundo, os sentimentos, a matemática) não são atitudes de um espírito, mas de um enfrentamento, quer dizer, de um corpo em situação que é a condição de possibilidade para tais fenômenos.

No entanto, a despeito de conceber a subjetividade pela ultrapassagem de si, Merleau-Ponty admite a necessidade de não anular o sujeito, procurando, desse modo, afirmar a existência de um em si indeclinável no horizonte de sua transcendência. Os pensamentos particulares construídos pelas experiências do sujeito com o mundo não devem esgotar sua subjetividade, visto que o pensamento "não é concebível sem um outro pensamento possível que seja seu testemunho" (MERLEAU-PONTY, 2011, p. 535).

Em outras palavras, se for verdade que existe consciência, que algo aparece para o sujeito, é verdade também que atrás de todos os pensamentos exista um em si. Segundo Ferraz (2006, p. 181), "sem esse segundo pensamento, o primeiro, ao se engajar nas coisas e não reconhecer a si mesmo, não seria pensado por ninguém e, portanto, não seria um pensamento". É, pois, por esse motivo que se faz necessário admitir a consciência de si, porquanto será a garantia de unificação entre os atos particulares e seus pensamentos extraídos da experiência. O que está em questão, aqui, para Merleau-Ponty (2011, p. 536), é o fato de compreender "como a subjetividade pode ser ao mesmo tempo dependente e indeclinável?".

É mediante a análise da linguagem que o filósofo buscará explicitar esse paradoxo. Tomando a leitura da Segunda Meditação de Descartes, exemplifica Merleau-Ponty (2011, p. 536), encontramos a descrição de um eu em ideia, mas não de um eu particular, mas um eu geral que se expressa essencialmente por intermédio da linguagem verbal. Nesse sentido, a existência somente se compreende após a linguagem exprimir tal fato. Se for verdade que a linguagem faz com que a expressão se anule em benefício do expresso, fazendo com que seu papel mediador acaba por ser esquecido, é verdade também que nossa existência em estado nascente tende a cair em esquecimento na medida em que a transpomos em ideia. Como diz Merleau-Ponty (2011, p. 537), "Descartes, e com mais razão ainda, o seu leitor começam a meditar em um universo já falante", ou seja, em um universo de ideias, cujos “objetos" dessas ideias estão em segundo plano, para não dizer esquecidos.

De acordo com Merleau-Ponty (2011, p. 538, grifos do autor):

O Cogito que nós obtemos lendo Descartes (e mesmo aquele que Descartes efetua em vista da expressão e quando, voltando-se para sua própria vida, ele a fixa, a objetiva e a 'caracteriza' como indubitável) é portanto um Cogito falado, posto em palavras, compreendido nas palavras e que, exatamente por essa razão, não alcança sua meta, já que uma parte de nossa existência, aquela que está ocupada em fixar conceptualmente nossa vida e em pensá-la como indubitável, escapa à fixação e ao pensamento.

Se não tivéssemos, antes de estarmos situados na linguagem, uma dimensão existencial, no sentido de estar em contato em um mundo pré-reflexivo, certamente nem poderíamos entender o que Descartes falou sobre o cogito, visto que esse somente é compreensível na medida em que encontramos em nós mesmos um cogito tácito, ou seja, um cogito encarnado no mundo. Para Merleau-Ponty (2011, p. 539, grifos do autor), "era esse Cogito silencioso que Descartes visava ao escrever as Meditações". Trata-se, aqui, de uma significação pré linguística, ou uma consciência não tética.

Para compreendermos, todavia, o cogito tácito é preciso, diz Merleau-Ponty (2011, p. 539), que não concebamos a linguagem como um produto da consciência e, da mesma maneira, nem a consciência como um produto da linguagem. A palavra, por exemplo, nunca se reduz à inscrição realizada no papel, bem como por meio da expressão verbal. Não obstante, reconhecemos a palavra em todas suas formas de aparição, embora jamais "se 
esgota nelas" (MERLEAU-PONTY, 2011, p. 539).

De acordo com Merleau-Ponty, o sujeito falante deve ser compreendido como lançado na fala sem representar as palavras que vai exprimir. A palavra, dessa maneira, deixa de ser concebida como representação do sujeito, passando a ter o estatuto de presença motora, de "modulação do corpo enquanto ser no mundo" (MERLEAU-PONTY, 2011, p. 540). Ademais, a palavra é assumida pelo sujeito como "potência falante, e em última análise, por uma potência motora que me foi dada com a primeira experiência de meu corpo e de seus campos perceptivos e práticos" (MERLEAU-PONTY, 2011, p. 540).

Sob esse prisma, considerando que a consciência não é produto da linguagem e nem a linguagem produto da consciência, é preciso admitir que haja um fundo existencial no qual o sujeito entra em contato com as coisas e com a linguagem de maneira silenciosa, ou, conforme Merleau-Ponty (2011, p. 541, grifo do autor), que "existe um cogito tácito, uma experiência de mim por mim".

No entanto, essa experiência de si mesmo somente se atesta a partir do momento em que se exprimiu para um horizonte transcendental do qual ela, a subjetividade, não determinou. Assim, de acordo com Merleau-Ponty (2011, 541), ela "só se conhece nas situações-limite em que está ameaçada". É compreensível, dessa maneira, o paradoxo da subjetividade, qual seja, de ser dependente e indeclinável. Ela é dependente por ser impossível saber-se sobre si mesma sem estar atrelada a uma dimensão de generalidade; indeclinável por ela não se extinguir frente à objetividade, a despeito de ser revelado por intermédio dela.

No exemplo proposto por Merleau-Ponty sobre dois amigos olhando para a mesma paisagem e cada qual apontando com seu dedo para um determinado ponto da natureza, fica claro como dois sujeitos podem ter experiências de um mesmo objeto sem que para isso o mundo seja reduzido à experiência de cada um, fazendo com que a experiência de um impeça a experiência de outrem. Mas isso somente é possível pelo fato de que "a universalidade e o mundo se encontram no coração da individualidade e do sujeito" (MERLEAU-PONTY, 2011, p. 544). Noutros termos:

O mundo é o campo de nossa experiência, e se nós somos apenas uma visão do mundo, pois agora a mais secreta vibração de nosso ser psicofísico já anuncia o mundo, a qualidade é o esboço de uma coisa, e a coisa é o esboço do mundo (MERLEAU-PONTY, 2011, p. 544, grifo do autor).

Com efeito, o cogito tácito somente se constata a partir da configuração que se dá por meio da relação intrínseca entre o individual e o coletivo, entre a solidão e a generalidade ou, em outras palavras, entre o fundante e fundado. Nesse sentido, a subjetividade indeclinável depende do horizonte compartilhado na medida em que é somente aí que ela se realiza: "Se o sujeito está em situação, se até mesmo ele não é senão uma possibilidade de situações, é porque ele só realiza sua ipseidade sendo efetivamente corpo e entrando, através desse corpo, no mundo" (MERLEAU-PONTY, 2011, p. 547, grifo nosso).

Assim, se, por um lado, é verdade que “outrem nunca existirá como nós mesmos, ele é sempre um irmão menor” (MERLEAU-PONTY, 2011, p. 580), nós nunca apreenderemos a ipseidade do outro; por outro, é verdade também que não podemos concluir daí que a relação com outrem está fadada ao fracasso, visto que o eu e o outro não são excludentes, mas coexistentes, mantendo cada qual sua singularidade.

\section{CONSIDERAÇÕES FINAIS}

Conforme vimos, o problema que Merleau-Ponty se depara, no texto da Fenomenologia da percepção, é o momento do "nascimento" do cogito, do em si. Pois, como sabemos, o grande impasse da relação com o outro é exatamente o problema de que o 
cogito impossibilita a existência de um outro que não esteja submetido a minha consciência. Assim, não há lugar, do ponto de vista cartesiano, para dois cogitos. Frente a isso, MerleauPonty realiza a minuciosa releitura da noção de cogito e evidencia que na base do cogito que Descartes postulou, há um cogito pré-reflexivo.

Trata-se, portanto, de retornar lá onde o cogito está encarnado, na primordialidade do 210 mundo, pois é aí que reside todo o campo natural que possibilita o pensamento tético exprimir suas significações. Segundo Dupond (2000, p. 281), isso não se encontra em Descartes, pois seu pensamento "se esquece da vida irrefletida na qual ele se enraíza". Daí advém a necessidade de "retornar à situação natural à qual a reflexão sucede" (DUPOND, 2000, p. 281), a fim esclarecer essa dimensão pré-objetiva. Mas, afinal de contas, como essa noção renovada de cogito poderá servir para a possibilidade da relação com o outro?

É oportuno esclarecer que o cogito pré-objetivo é, ao mesmo tempo, fundante e fundado pelo cogito falado. É fundante porque o cogito falado pressupõe a "consciência silenciosa" que antecede suas projeções. Porém, ele é ao mesmo tempo fundado pelo cogito falado, já que é por meio dele que se poderá exprimir essa vida silenciosa. É diante dessa perspectiva que Merleau-Ponty assegura a relação com o outro, pois a subjetividade deixa de ser uma entidade desprendida de um corpo, do mundo e do tempo, e passa a ser pensada como existente somente por meio dessas instâncias. Contudo, não apenas delas, como também do outro. Pois é através de certa "tensão necessária" com o outro que posso reconhecer a mim mesmo. Na obra de 1945, portanto, a subjetividade é caracterizada pela "generalidade" e, concomitantemente, pela "individualidade", figurando, desse modo, a perpétua dialética que sustenta as relações.

\section{REFERÊNCIAS}

DESCARTES, René. Meditações metafísicas. 2. ed. São Paulo: Martins Fontes, 2005.

DIAS, Isabel Matos. Elogio do sensivel: corpo e reflexão em Merleau-Ponty. Lisboa: Litoral Edições, 1989.

DUPOND, Pascal. Du cogito tacite au cogito vertical. Chiasmi Internacional. Paris, n. 2. p. 281$300,2000$.

MERLEAU-PONTY, Maurice. Signos. São Paulo: Martins Fontes, 1991. . Conversas: 1948. São Paulo: Martins Fontes, 2004. A estrutura do comportamento. São Paulo: Martins Fontes, 2006. Fenomenologia da percepção. 4. ed. São Paulo: Martins Fontes, 2011. O visivel e o invisível. 4. ed. São Paulo: Perspectiva, 2014.

MOUTINHO, Luiz Damon Santos. Razão e experiência: ensaio sobre Merleau-Ponty. São Paulo: Unesp, 2006.

O sensível e o inteligível: Merleau-Ponty e o problema da racionalidade. Kriterion: Revista de Filosofia, Belo Horizonte, v. 45, n. 110, p. 264-293, jul./dez., 2004.

FERRAZ, Marcus Sacrini Ayres. O transcendental e o existente em Merleau-Ponty. São Paulo: Associação Editorial Humanitas - FAPESP, 2006.

SILVA, Claudinei Aparecido de Freitas. A carnalidade da reflexão: ipseidade e alteridade em Merleau-Ponty. São Leopoldo: Nova Harmonia, 2009. 